\title{
ASSOCIATIONS OF GENE VARIATIONS IN NEUROPEPTIDE Y AND BRAIN DERIVED NEUROTROPHIC FACTOR GENES WITH POSTTRAUMATIC STRESS DISORDER
}

\author{
Elma Ferić Bojić ${ }^{1}$, Sabina Kučukalić², Alma Džubur Kulenović², Esmina Avdibegović ${ }^{3}$, \\ Dragan Babić ${ }^{4}$, Ferid Agani ${ }^{5}$, Miro Jakovljević ${ }^{6}$, Abdulah Kučukalić ${ }^{2}$, Alma Bravo Mehmedbašić ${ }^{2}$, \\ Emina Šabić Džananović ${ }^{2}$, Nermina Kravic ${ }^{3}$, Romana Babić ${ }^{4}$, Marko Pavlović ${ }^{4}$, \\ Branka Aukst Margetic ${ }^{7}$ Nenad Jaksic $^{6}$, Ana Cima Franc ${ }^{6}$, Dusko Rudan ${ }^{6}$, Shpend Haxhibeqiri $^{8}$, \\ Aferdita Goci Uka ${ }^{9}$, Blerina Hoxha ${ }^{9}$, Valdete Haxhibeqiri ${ }^{10}$, Mirnesa Muminović Umihanić ${ }^{11}$, \\ Osman Sinanović ${ }^{12}$, Nada Božina ${ }^{13}$, Christiane Ziegler ${ }^{14}$, Christiane Wolf $^{15}$, Bodo Warrings ${ }^{15}$, \\ Katharina Domschke ${ }^{14}$, Jürgen Deckert ${ }^{15}$ \& Damir Marjanović ${ }^{1}$ \\ ${ }^{l}$ Department of Genetics and Bioengineering, International Burch University, Sarajevo, Bosnia and Herzegovina \\ ${ }^{2}$ Department of Psychiatry, Clinical Center University Sarajevo, Sarajevo, Bosnia and Herzegovina \\ ${ }^{3}$ Department of Psychiatry, University Clinical Center of Tuzla, Tuzla, Bosnia and Herzegovina \\ ${ }^{4}$ Department of Psychiatry, University Clinical Center of Mostar, Mostar, Bosnia and Herzegovina \\ ${ }^{5}$ Faculty of Medicine, University Hasan Prishtina, Prishtina, Kosovo \\ ${ }^{6}$ Department of Psychiatry, University Hospital Centre Zagreb, Zagreb, Croatia \\ ${ }^{7}$ Department of Psychiatry, University Hospital Centre Sestre Milosrdnice, Zagreb, Croatia \\ ${ }^{8}$ Institute of Kosovo Forensic Psychiatry, University Clinical Center of Kosovo, Prishtina, Kosovo \\ ${ }^{9}$ Department of Psychiatry, University Clinical Centre of Kosovo, Prishtina, Kosovo \\ ${ }^{10}$ Department of Biochemistry, University Clinical Centre of Kosovo, Prishtina, Kosovo \\ ${ }^{11}$ Community Health Center Zivinice, Zivinice, Bosnia and Herzegovina \\ ${ }^{12}$ Department of Neurology, University Clinical Center of Tuzla, Tuzla, Bosnia and Herzegovina \\ ${ }^{13}$ Department of Laboratory Diagnostics, University Hospital Center Zagreb, Zagreb, Croatia \\ ${ }^{14}$ Department of Psychiatry and Psychotherapy, University Hospital Freiburg, Freiburg, Germany \\ ${ }^{15}$ Department of Psychiatry, Psychosomatics and Psychotherapy, Center of Mental Health, \\ University Hospital Wurzburg, Wurzburg, Germany
}

received: 31.1.2019;

revised: 13.5.2019;

accepted: 29.5 .2019

\section{SUMMARY}

Background: Individuals who are exposed to traumatic events are at an increased risk of developing posttraumatic stress disorder (PTSD), a condition during which an individual's ability to function is impaired by emotional responses to memories of those events. The gene coding for neuropeptide $Y(N P Y)$ and the gene coding for brain-derived neurotrophic factor (BDNF) are among the number of candidate gene variants that have been identified as potential contributors to PTSD. The aim of this study was to investigate the association between NPY and BDNF and PTSD in individuals who experienced war-related trauma in the South Eastern Europe (SEE) conflicts (1991-1999).

Subjects and methods: This study included participants with current and remitted PTSD and healthy volunteers (N=719, 232 females, 487 males), who were recruited between 2013 and 2015 within the framework of the South Eastern Europe (SEE) - PTSD Study. Psychometric methods comprised the Mini International Neuropsychiatric Interview (M.I.N.I.), the Clinician Administered PTSD Scale (CAPS), and the Brief Symptom Inventory (BSI). DNA was isolated from whole blood and genotyped for NPY rs5574 via $P C R$ - RFLP and NPY rs 16147 and BDNF rs6265 using the KASP assay.

Results: Tests for deviation from Hardy-Weinberg equilibrium showed no significant results. Analyses at the categorical level yielded no associations between the affected individuals and all three SNPS when compared to controls. Within lifetime PTSD patients, the major alleles of both NPY variants showed a nominally significant association with higher CAPS scores ( $p=0.007$ and $p=0.02$, respectively). Also, the major allele of $r 55574 C>T$ was associated with higher BSI scores with a nominal significance among current PTSD patients $(p=0.047)$. The results did not withstand a Bonferroni adjustment $(\alpha=0.002)$.

Conclusion: Nominally significant associations between NPY polymorphisms and PTSD susceptibility were found that did not withstand Bonferroni correction.

Key words: posttraumatic stress disorder - neuropeptide $Y$ - brain-derived neurotrophic factor - war-induced trauma

\section{INTRODUCTION}

Posttraumatic stress disorder (PTSD) is classified under the Trauma-and Stress-related Disorders category, and it is defined as a condition that is subsequent to a stressor, or a traumatic event that triggered the onset of the disease (American Psychiatric Association 2013). The majority of trauma victims experience symptoms that are defined by three symptom clusters, namely reexperiencing in the form of flash-backs, intrusions or 
nightmares, avoidance and numbing and arousal, all of which have to last for more than one month after experiencing or witnessing extreme trauma or stress that is characterized by actual or perceived threat of death or serious injury or threat to one's physical integrity (American Psychiatric Association 1994). For a small minority, PTSD symptoms persist and develop into clinical PTSD. The annual prevalence of PTSD has been reported to be $4.7 \%$, and the lifetime prevalence about $6.1 \%$ (Goldstein et al. 2016), and higher prevalence rates of about $13 \%$ are observed among combat veterans (U.S. Department of Veterans Affairs 2015). Other studies report that about $5 \%$ of those exposed to a trauma develop clinically relevant PTSD (Breslau \& Kessler 2001, Kessler et al. 1995). The lifetime prevalence of PTSD in the US general population is an estimated 7\% (Kessler et al. 2005), while it is as high as $35 \%$ in individuals who experienced the war in Bosnia and Herzegovina (Priebe et al. 2004).

One candidate gene that has been studied is Neuropeptide Y (NPY). Isolated and sequenced in 1982, peptide expression distribution of NPY is found throughout the central and peripheral nervous system (Adrian et al. 1983, Allen et al. 1983). NPY is derived from the 97 amino-acid pro-hormone, pre-pro-NPY after enzymatic processing by peptidase enzymes (Brakch et al. 1997, Grouzmann \& Brakch 2005). It is a 36-amino acid peptide that shares its sequence homology with the NPY hormone family which encompasses enteric peptides, pancreatic polypeptide (PP) as well as peptide YY (PYY) that share a hairpin-like structure called the PPfold (Gehlert 2004, Tatemoto et al. 1982). An analysis of NPY mRNA in human brain tissue indicated its abundance in the neocortex, polymorphic layer of the dentate gyrus, basal ganglia, and amygdala (Caberlotto et al. 2000). Furthermore, expression analyses demonstrate high NPY peptide expression in cell bodies and fibers within the amygdala, nucleus accumbens (NAcc), various hypothalamic nuclei, cortex, and hippocampus within the human brain (Adrian et al. 1983).

Levels of NPY peptide-like immunoreactivity in PTSD subjects are direct evidence for the relevance of the neuropeptide Y in PTSD pathophysiology. Sah et al. reported lower cerebrospinal fluid (CSF) NPY levels in Vietnam (2009) and Iraq/Afghanistan (2014) veterans with combat-related PTSD. Other examples of comorbidities related to PTSD were studied by Huang \& Reichardt (2015) and Xu et al. (2012), who demonstrated that reduced CSF NPY can be observed in individuals with insomnia and substance dependence, respectively, while increased amounts of CSF NPY were reported by Coccaro et al. (2012) in individuals with impulsive aggression. In addition to CSF analyses, plasma levels of NPY were investigated as well. Rasmusson et al. (2000) found reduced neuropeptide levels in PTSD patients, while Morgan et al. (2002) found no difference between PTSD patients and controls. A possible association between NPY and both high coping and re- silience has been demonstrated in a study in which significantly higher plasma NPY levels were reported in individuals who had PTSD in the past but are currently otherwise symptom free (Yehuda et al. 2006).

Studies conducted in postmortem brain and lymphoblasts as well as plasma NPY peptide levels have helped establish a predictive relationship between NPY haplotypes and low and high expression of NPY messenger RNA (mRNA) (Zhou et al. 2008). Zhou et al. (2008) also reported lower haplotype-driven NPY expression in association with high emotion-induced activation of the amygdala, higher trait anxiety, and diminished pain/ stress-induced activations of the endogenous opioid neurotransmission in various brain regions. Witt et al. (2011) investigated rs16147 in conjunction with early adversity and found that it modulates stress responses in young adults. Domschke et al. (2012) found that rs16147 contributes to stronger bilateral amygdala activation and slower treatment response in anxious depression patients. Postmortem sample analyses by Sommer et al. (2010) demonstrated that NPY rs16147 correlated with higher prefrontal expression, while a separate epidemiological sample in the same study showed an association of rs16147 with negative affect in individuals exposed to high adversity. Another NPY variant that has been studied is rs5574, a $5671 \mathrm{C} / \mathrm{T}$ polymorphism on chromosome 7 position 24289514. Several groups have investigated it in regard to PTSD or other conditions that are in either direct or indirect connection with the disease. Furthermore, Tiwari et al. (2013) have investigated the effect of several SNPs on antipsychotic-induced body weight gain (BWG), and they have found that rs5574 is significantly associated with weight change in schizophrenic patients. Also, the rs5574 was reported in association with alcohol dependent individuals who experienced withdrawal with seizures (Okubo \& Harada 2001). Zhou et al. (2008) have found low NPY expression in amygdala and hippocampus activation studies associated with rs5574 haplotypes. Also, one study was not able to replicate the contribution of NPY gene haplotypes to trait anxiety (neuroticism) (Cotton et al. 2009).

In recent years, an association between BDNF and numerous psychiatric disorders like anxiety, depression, eating disorders and posttraumatic stress disorder has been established (Chen et al. 2006). BDNF is a member of the neurotrophin family important for neuronalbirth, maturation, differentiation, migration, survival and plasticity (Huang \& Reichhardt 2001). Other studies have shown that BDNF is important for stress response and the related reaction as well as behavior (Liu et al. 2005). It is hypothesized that BDNF is responsible for the antidepressant effect of psychopharmacological drugs often used in the treatment of stress-related disorders (Tsai 2007, Jiang et al. 2017). In humans, the singlenucleotide BDNF rs6265 (Val66Met) polymorphism leads to an exchange of amino acids from valine (Val) to methionine (Met) at codon 66 (Egan et al. 2003, 
Thoenen 1995). The frequency of the BDNF Met allele is relatively common and is ethnically stratified. The highest frequency of carriers has been observed among the Asian population (estimated 50\%) and the least in African American individuals (estimated 4\%) (Shimizu et al. 2004, Pivac et al. 2009). It seems that either the heterozygous or homozygous Met allele leads to significantly less BDNF release than the Val allele (Chiaruttini et al. 2009, Egan et al. 2003). BDNF availability in the brain is critical for the formation of new memories after stress exposure (Peters et al. 2010). Also, a reduced activity-dependent secretion of BDNF has been associated with the BDNF Met allele (Egan et al. 2003). These changes in levels of BDNF in the brain decrease synaptic plasticity in the prefrontal cortex (PFC) and thereby lead to the deficiency of new memories required for fear extinction. Forming new memories associated with the stimulus that was previously paired with a fearful event with one that signals safety is thought to be involved in erasing fearful memories, and this task is extremely important for stress-related disorders. A translational study found that BDNF Met allele carriers have intact fear conditioning but differential extinction of a learned fear response (Soliman et al. 2010). This study showed that there is a difference in how BDNF Met allele carriers and noncarriers recruit the amygdala and ventromedial PFC. Neuroimaging studies of PTSD probands have shown a similar pattern of increased amygdala activation and decreased medial PFC activation (Kremen et al. 2012, Protopopescu et al. 2005). As it seems that fear extinction is an issue specifically related to BDNF, this could have effects not only on the symptom development but on the treatment course as well. The success of exposure therapy, as one of the best psychotherapeutic approaches in PTSD, might then be affected by the BDNF allelic state. This means that Met allele carriers might not readily respond to this psychotherapy. Zhang et al. (2016) reported that the Val66Met polymorphism shapes PTSD symptom development and as such influences PTSD diagnosis.

Given the aforementioned, it is safe to state that data gathered to date suggest that genetic variation in NPY (Schmeltzer et al. 2016) and BDNF (Chen et al. 2006) expression may promote inter-individual differences in stress and emotional responses to trauma that are relevant in determining PTSD susceptibility or resilience following a traumatic event. It is hypothesized that NPY rs16174, rs5574 and BDNF rs6265 are correlate with both PTSD diagnosis as well as severity.

\section{SUBJECTS AND METHODS}

\section{Subjects}

The participants were inhabitants of South Eastern Europe (SEE) recruited between 2013 and 2015 at research centers in Sarajevo, Prishtina, Tuzla, Zagreb and Mostar under a Stability Pact for the SEE collaborative research study "Molecular Mechanisms of
Posttraumatic Stress Disorder", supported by the DAAD (Deutscher Akademischer Austausch Dienst). Methods regarding recruitment, diagnostic assessment, inclusion and exclusion criteria, as well as sample size and gender distribution were previously described (Dzubur Kulenovic et al. 2016).

The five psychiatric centers involved in the recruitment were in countries whose population has experienced severe war-related trauma between 1991 and 1999: Zagreb in Croatia (1991-1992), Sarajevo, Tuzla and Mostar in Bosnia-Herzegovina (1992-1995) and Prishtina in the Republic of Kosovo (1998-1999). The cohort comprises several participant groups, namely those who developed PTSD, those who did not and those who had developed the disease and eventually recovered. A few participants in the control group had no exposure to trauma at all. Of the 747 recruited individuals 719 (mean age $49.4 \pm 7.9 ; 232$ females and 487 males) could be included in this study. The experimental group comprised 218 participants with current PTSD (mean age 50.1 \pm 6.7 ; 61 females and 157 males), 151 participants with lifetime PTSD (mean age 49.5 $\pm 8.2 ; 53$ females and 98 males), and 350 participants with no diagnosable PTSD (mean age 48.8 \pm 8.5 ; 118 females and 232 males) (Dzubur Kulenovic et al. 2016).

\section{Ethical Votes}

Ethical votes at the participating clinical centers were obtained between 2011 and 2013 on the basis of local translations of an information and consent formdesigned by the Würzburg center.

Thus, participants were informed and gave written informed consent according to the principles of the Declaration of Helsinki (WMA 2013).

\section{Psychometric Instruments}

To clarify the presence or absence of PTSD symptoms, the Mini International Neuropsychiatric Interview (M.I.N.I.) was used. For categorization of PTSD symptoms between current and lifetime, the Clinician Administrated PTSD Scale (CAPS) (Blake et al. 1996) was assessed, and for measurement of general psychiatric symptoms the Brief Symptom Inventory (BSI) (Derogatis \& Melisaratos 1983) was used.

\section{Molecular Analyses}

Genomic DNA was isolated from frozen venous EDTA-blood according to manufacturer's instructions using the FlexiGene DNA Kit (Qiagen, Hilden, Germany) and stored at $-80^{\circ} \mathrm{C}$ until genotyping at the Laboratory of Functional Genomics in Würzburg.

NPY rs5574 was genotyped using the following PCR-RFLP procedure conditions: DNA was amplified by PCR with the oligonucleotide primers F: 5'GCTTGTTACAGATGAACACCTGAC-3' and R: 5'TGTCATACCGAGTTCTGGGAACA-3' in a $25 \mu 1$ 
reaction volume containing 45-65 ng genomic DNA, $0.4 \mathrm{mM}$ of each primer, $0.1 \mathrm{mM}$ of each nucleotide, $0.75 \mathrm{mM} \mathrm{MgCL}_{2}$ and $0.5 \mathrm{U}$ Taq DNA polymerase. The following cycler conditions were used: 5 min denaturation at $95^{\circ} \mathrm{C}$, followed by 40 cycles of $45 \mathrm{~s}$ at $95^{\circ} \mathrm{C}, 45 \mathrm{~s}$ at $63^{\circ} \mathrm{C}$ and $45 \mathrm{~s}$ at $72^{\circ} \mathrm{C}$ and a final extension step of 5 min at $72^{\circ} \mathrm{C}$. PCR fragments $(217 \mathrm{bp})$ were digested for 4 $\mathrm{h}$ at $37^{\circ} \mathrm{C}$ with the restriction endonuclease BfaI (NEB, Frankfurt a. Main, Germany) resulting in differentially sized fragments for each genotype. The fragments were separated on a $3 \%$ agarose gel by electrophoresis and visualized with ethidium bromide. Fragment lengths and resulting genotypes were determined by two independent investigators blinded for diagnosis. NPY rs16147 genotypes were determined using a custom designed KASP genotyping assay (LGC, Berlin, Germany). PCR reaction including an end-point fluorescent read-out was performed according to manufacturers' instructions in a CFX384 Touch Cycler (Biorad, Munich, Germany). Genotype analysis was conducted using CFX Manager.

BDNF rs6265 (Val66Met) genotyping was performed according to previously published protocols (Mühlberger et al. 2014).

\section{Statistical Analyses}

Statistics were performed using PLINK 1.9. All three SNPs were polymorphous (minor allele frequency $\geq 10 \%$ ), reached a minimal genotyping call rate of $98 \%$ and did not deviate from Hardy-Weinberg equilibrium $(p \geq 0.1)$. Logistic regression was used for case-control analyses. Within the two groups of patients, i.e. individuals with lifetime or current PTSD, linear regression was carried out for analyses on the dimensional CAPS and BSI scores. The additive allelic, dominant (based on the minor allele), genotypic models were tested in all phenotypes. The significance level was Bonferroni adjusted for 23 variants that were analyzed in total within the entire project $(\alpha=0.002)$ (Dzubur Kulenovic et al. 2016).

\section{RESULTS}

The influence of genotypes on the dimensional CAPS and BSI questionnaires, both linked to PTSD, was determined in all cases with current and lifetime PTSD symptoms. An overview of all genotyped SNPs, along with their minor and major alleles, minor allele frequency and the $\mathrm{R}^{2}$-value for linkage disequilibrium (LD) between both NPY variants is given in (Table 1).

\section{Neuropeptide $Y$}

Case-control analyses for the three calculated models revealed no detectable impact of NPY rs5574 on the categorical phenotype of PTSD ( $\left.p_{\text {all }}>0.05\right)$. However, its influence on dimensional average CAPS scores showed nominal significant differences $\left(\mathrm{p}_{\text {allelic }}=0.0206\right.$; $\mathrm{p}_{\text {genotypic }}=0.0235 ; \mathrm{P}_{\text {dominant }}=0.0068$; Table 2; Figure 1) in patients suffering from lifetime PTSD, always with the major (C) allele conveying genetic risk. These findings could not be replicated in patients with diagnosed current PTSD ( $\left.\mathrm{p}_{\mathrm{all}}>0.05\right)$. In contrast, the average current BSI score of NPY rs5574 C allele homozygotes was higher with a nominal significance $\left(\mathrm{p}_{\text {dominant }}=0.0474\right.$; Table 2; Figure 1) than that of T allele carriers, while in this questionnaire patients with lifetime PTSD show no associations ( $\left.\mathrm{p}_{\mathrm{all}}>0.05\right)$. None of detected nominal associations withstood Bonferroni correction.

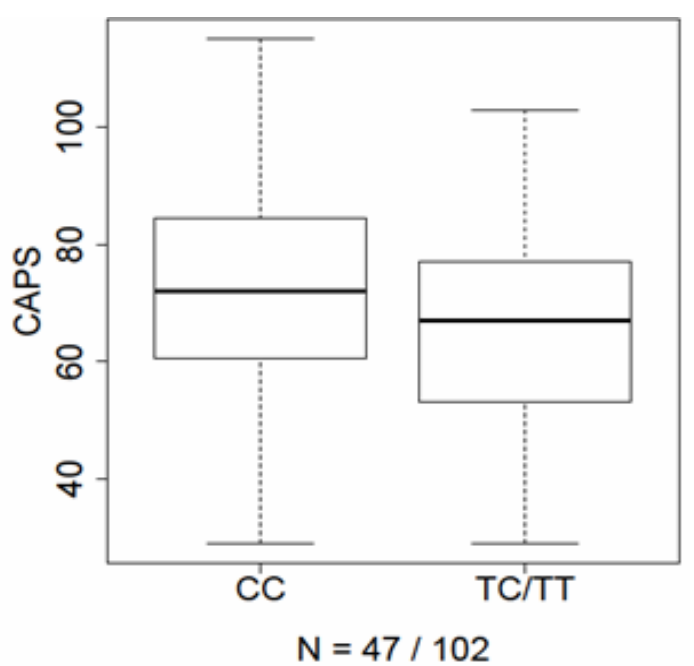

Figure 1. Distribution of CAPS values of NPY rs5574 lifetime PTSD subjects according to genotypes in the dominant model.

Because of the high LD $\left(\mathrm{R}^{2}=0.84\right)$ between both analyzed NPY variants, rs16147 was in concordance with rs5574 and not associated with the categorical diagnoses but with the dimensional average lifetime PTSD CAPS values for the allelic and the dominant model at a nominal level $\left(\mathrm{p}_{\text {allelic }}=0.0470 ; \mathrm{p}_{\text {dominant }}=0.0226\right.$; Table 3) and for the genotypic model at a marginal level $\left(\mathrm{p}_{\text {genotypic }}=0.0709\right.$; Table 3 ), also with the major $(\mathrm{T})$ allele conveying genetic risk. No further associations with dimensional phenotypes were observed for this variant (see Table $3 ; \mathrm{p}>0.05$ ).

Table 1. Minor Allele Frequencies for NPY rs5574 and rs16147 and BDNF rs6265

\begin{tabular}{lccccc}
\hline Gene & SNP & Minor Allele & Major Allele & MAF & LD \\
\hline NPY & rs5574 & T & C & 0.43 & 0.84 \\
NPY & rs16147 & C & T & 0.46 & \\
BDNF & rs6265 & A & G & 0.17 & \\
\hline
\end{tabular}

$\mathrm{SNP}=$ Single Nucleotide Polymorphism; MAF = Minor Allele Frequency; LD = Linkage Disequilibrium 
Table 2. NPY rs5574 association results, along with genotype and allele counts, for individuals in analysis, CAPS and BSI means and standard deviations, as well as nominal p-values of regression analyses

\begin{tabular}{|c|c|c|c|c|c|c|c|}
\hline \multirow{2}{*}{ NPY rs5574 } & \multicolumn{2}{|c|}{ Allelic Model } & \multicolumn{3}{|c|}{ Genotypic Model } & \multicolumn{2}{|c|}{ Dominant Model } \\
\hline & $\mathrm{T}$ & $\mathrm{C}$ & TT & $\mathrm{TC}$ & $\mathrm{CC}$ & TT/TC & $\mathrm{CC}$ \\
\hline Controls & 290 & 400 & 65 & 160 & 120 & 225 & 120 \\
\hline PTSD $_{\text {lifetime }}$ & 128 & 170 & 26 & 76 & 47 & 102 & 47 \\
\hline PTSD $_{\text {current }}$ & 195 & 233 & 44 & 107 & 63 & 151 & 63 \\
\hline $\mathrm{P}_{\text {case-control-value }}$ & \multicolumn{2}{|c|}{0.3023} & \multicolumn{3}{|c|}{0.8081} & \multicolumn{2}{|c|}{0.571} \\
\hline $\mathrm{CAPS}_{\text {lifetime }}($ mean $\pm \mathrm{SD})$ & $64.3 \pm 16.5$ & $69.0 \pm 18.1$ & $64.2 \pm 15.4$ & $64.3 \pm 17.2$ & $72.7 \pm 17.9$ & $64.3 \pm 16.7$ & $72.7 \pm 17.9$ \\
\hline $\mathrm{P}_{\mathrm{CAPS}}$-value & \multicolumn{2}{|c|}{0.0206} & \multicolumn{3}{|c|}{0.0235} & \multicolumn{2}{|c|}{0.0068} \\
\hline $\mathrm{BSI}_{\text {current }}($ mean $\pm \mathrm{SD})$ & $109.8 \pm 46.6$ & $116.5 \pm 45.6$ & $111.3 \pm 43.3$ & $108.6 \pm 49.0$ & $123.3 \pm 41.4$ & $109.4 \pm 47.5$ & $123.3 \pm 41.4$ \\
\hline $\mathrm{P}_{\mathrm{BSI}}$-value & \multicolumn{2}{|c|}{0.1355} & \multicolumn{3}{|c|}{0.3163} & \multicolumn{2}{|c|}{0.0474} \\
\hline
\end{tabular}

Table 3. NPY rs16147 association results, along with genotype and allele counts, for individuals in analysis, CAPS and BSI means and standard deviations, as well as nominal p-values

\begin{tabular}{|c|c|c|c|c|c|c|c|}
\hline \multirow{2}{*}{ NPY rs16147 } & \multicolumn{2}{|c|}{ Allelic Model } & \multicolumn{3}{|c|}{ Genotypic Model } & \multicolumn{2}{|c|}{ Dominant Model } \\
\hline & $\mathrm{C}$ & $\mathrm{T}$ & $\mathrm{CC}$ & CT & TT & $\mathrm{CC} / \mathrm{CT}$ & TT \\
\hline Controls & 303 & 385 & 73 & 157 & 114 & 230 & 114 \\
\hline PTSD $_{\text {lifetime }}$ & 134 & 162 & 30 & 74 & 44 & 104 & 44 \\
\hline PTSD $_{\text {current }}$ & 209 & 215 & 54 & 101 & 57 & 155 & 57 \\
\hline $\mathrm{P}_{\text {case-control-value }}$ & \multicolumn{2}{|c|}{0.1473} & \multicolumn{3}{|c|}{0.3064} & \multicolumn{2}{|c|}{0.5999} \\
\hline $\mathrm{CAPS}_{\text {lifetime }}($ mean $\pm \mathrm{SD})$ & $64.8 \pm 16.7$ & $68.9 \pm 18.3$ & $64.5 \pm 15.1$ & $65.0 \pm 17.8$ & $72.2 \pm 18.0$ & $64.9 \pm 17.1$ & $72.2 \pm 18.0$ \\
\hline $\mathrm{P}_{\text {CAPS-value }}$ & \multicolumn{2}{|c|}{0.0470} & \multicolumn{3}{|c|}{0.0709} & \multicolumn{2}{|c|}{0.0226} \\
\hline $\mathrm{BSI}_{\text {current }}($ mean $\pm \mathrm{SD})$ & $111.5 \pm 47.5$ & $115.2 \pm 45.2$ & $114.1 \pm 47.6$ & $111.5 \pm 47.5$ & $115.2 \pm 45.2$ & $114.1 \pm 47.6$ & $123.3 \pm 41.4$ \\
\hline $\mathrm{P}_{\mathrm{BSI} \text {-value }}$ & \multicolumn{2}{|c|}{0.4358} & \multicolumn{3}{|c|}{0.1314} & \multicolumn{2}{|c|}{0.1688} \\
\hline
\end{tabular}

CAPS = Clinician Administered PTSD Scale; $\quad$ BSI = Brief Symptom Inventory； SD = standard deviation;

Italics indicates $p \leq 0.05$

\section{Brain-Derived Neurotrophic Factor}

No significant associations were identified within the additive allelic genotypic and dominant models for BDNF rs6265 for dimensional or categorical phenotypes $\left(p_{\text {all }}>0.05\right)$.

\section{DISCUSSION}

To our knowledge, this is the first study to report an association between PTSD severity and NPY rs5574 and rs16147. Other studies have reported different NPY expression levels associated with the variants (Björk et al. 2010, Hansson et al. 2006; Heilig 2004, Nikisch et al. 2005, Sah \& Geracioti 2013, Schmeltzer et al. 2016, Sommer et al. 2010, Widerlöv et al. 1988, Zhou et al. 2008), but no clinical data has been published to date. Furthermore, a study reported that combat soldiers were more resilient to trauma when their NPY levels were higher (Nulk et al. 2011). It has also been hypothesized that NPY tones down the excitatory pro-stress neurotransmitters (Eaton et al. 2007, Heilig et al. 1994, Sah \& Geracioti 2013), and this is supported by research that demonstrates that NPY is found within the same neuroanatomical brain structures as corticotropin-releasing factor (CRF) and norepinephrine (NE) yet having opposite functions to pro-stress neurotransmitters (Kask et al. 2002, Sah \& Geracioti 2013, Sajdyk et al. 2004). The lower CAPS scores for NPY rs5574 T-allele carriers could be interpreted that the $\mathrm{T}$ allele serves as a protective allele, while for the NPY rs16174 the C allele has that role. We interpret our genetic findings of rs5574 and rs16174 thus as partly a continuation of and in line with what has already been reported.

While lower lifetime CAPS and current BSI scores are found in both NPY rs5574 T-allele and rs16174 Callele carriers, it is definitively somewhat puzzling that CAPS scores are associated among the lifetime cohort and the BSI scores are associated within the current PTSD cohort. Given that the two patient groups are not the same, this finding just further supports the protective function of the two alleles. Furthermore, he fact that CAPS and BSI scores are differentially significant between individuals who have reported having had PTSD at some point in their lives and who have reported having it at the time of the interview may highlight the chronological factor between PTSD and genetics and begs the question whether the same trends would hold up if the same patient cohort were studied over an extended period of time. Certainly, the time at which trauma was experienced could affect the genetic underpinnings of PTSD. As the conditions under which blood was drawn alone are enough to affect NPY expression, epigenetic changes may confound genetic associations 
(Sah et al. 2009, Zhou et al. 2008). Also, given that NPY has been reported to modulate contextual fear and learning as well as memory, together with its anxietymodulating properties, it could be argued that the chronological effects between the two alleles have something to do with how the trauma was processed.

The present findings should be interpreted in light of some overall limitations. The patient cohort is fairly small, and trauma type and intensity is different among the centers of this study. Also, the ethnic and cultural heterogeneity between centers may have increased confounding by epigenetic factors. Overall, more research is needed to comprehend the pathways that connect genetic factors and the risk of developing PTSD. Studies within the context of even larger consortia, e.g. psychiatric genomic consortia, are necessary. This may, in turn, facilitate the development of either improved or entirely novel treatments and prevention methods for this common and debilitating disorder.

\section{CONCLUSION}

We hypothesized that NPY rs16174, rs5574 and BDNF rs6265 are correlated both with PTSD diagnosis as well as severity. Correlations were found with both NPY SNPs did not withstand which howeve the Bonferroni correction. No significant findings were found with the BDNF rs6265.

\section{Acknowledgements:}

We thank all the participants and their families without whose idealistic and enthusiastic support the study would not have been possible. We also would like to thank at Sarajevo: the Association of Women Victims of War and Bakira Hasecic, the Association of Physically Handicapped, Zilko Buljugija, Zoran Budimlija, MD, PhD, Jasminka Krehic, MD, PhD, Elvira Sabanovic, RSN and Subhija Gusic; in Kosovo: Feride Rushiti, MD, Selvije Izeti, MSc, Vjosa Devaja, MD, Melita Kallaba, MD from Kosova Rehabilitation Center for Trauma Survivors- KRCT; Emirjeta Kumnova, Veprore Shehu from Medica Kosova; Zahrije Podrimqaku Subashi from the Association of Political Prisoners, Kadire Tahiraj from the Center for Promotion of Women's Rights; Arbërore Ulaj, MD, Teuta Haxhiu, MD and Drita Gashi, MD, for their assistance in recruiting and interviewing participants; at Zagreb: Mirica Mavracic, Zoran Bradas, Zrinka Mirkovic and Maja Mezak Herceg for technical assistance in drawing blood and extracting DNA; at Tuzla: the staff of the Department of Transfusion of University Clinical Center of Tuzla, and the staff of the Department of Psychiatry, in particular Emina Hujdur, Medin Omerašević and Avdo Šakušić, MD for technical support and Maja Brkić and Sandra Zornić for their assistance in data collection; at Würzburg: Carola Gagel for technical assistance with extracting DNA. Thanks are highly deserved by and gratefully extended to Peter Riederer as spiritus rector who brought the consortium together. The study was funded by the DAAD program Stability Pact for South Eastern Europe and supported by the DFG-funded RTG 1253 (speaker Pauli) as well as the DFG-funded CRC-TRR58 (projects C02 Domschke, Deckert, and Z02 Deckert, Domschke).

Conflict of interest: None to declare.

\section{Contribution of individual authors:}

Each author has actively participated in the international research project (see Acknowledgments) and, therefore, has substantially contributed to the development and publication of this manuscript.

\section{References}

1. Adrian TE, Allen JM, Bloom SR, Ghatei MA, Rossor MN, Roberts GW et al.: Neuropeptide Y distribution in human brain. Nature 1983; 306:584

2. Allen YS, Adrian TE, Allen JM, Tatemoto K, Crow TJ, Bloom SR et al.: Neuropeptide $Y$ distribution in the rat brain. Science 1983; 221:877-879

3. American Psychiatric Association: Diagnostic and statistical manual of mental disorders, (3rd ed.). Washington, DC. 1984

4. American Psychiatric Association: Diagnostic and statistical manual of mental disorders, (5th ed.). Washington, DC, 2013

5. Björk K, Hansson AC \& Sommer WH: Functional Plasticity and Genetic Variation: Insights into the Neurobiology of Alcoholism 2010; 91:129

6. Blake DD, Weathers FW, Nagy LM, Kaloupek DG. The development of a Clinician-Administered PTSD Scale. Journal of Traumatic Stress. 1995; 8:75-90

7. Brakch N, Rist B, Beck-Sickinger AG, Goenaga J, Wittek $R$, Bürger $E$ et al.: Role of prohormone convertases in pro-neuropeptide $Y$ processing: coexpression and in vitro kinetic investigations. Biochemistry 1997; 36:16309-20

8. Breslau $N$ \& Kessler RC: The stressor criterion in DSMIV posttraumatic stress disorder: an empirical investigation. Biological psychiatry 2001; 50:699-704

9. Caberlotto L, Fuxe $K$ \& Hurd YL: Characterization of NPY mRNA-expressing cells in the human brain: colocalization with Y2 but not Y1 mRNA in the cerebral cortex, hippocampus, amygdala, and striatum. Journal of Chemical Neuroanatomy 2000; 20:327-337

10. Chen ZY, Jing D, Bath KG, Ieraci A, Khan T, Siao CJ et al.: Genetic variant BDNF (Val66Met) polymorphism alters anxiety-related behavior. Science 2006; 314:140-143

11. Chiaruttini C, Vicario A, Li Z, Baj G, Braiuca P, Wu Y et al.: Dendritic trafficking of BDNF $m R N A$ is mediated by translin and blocked by the G196A (Val66Met) mutation. Proceedings of the National Academy of Sciences 2009; 106:16481-16486

12. Coccaro EF, Lee R, Liu T \& Mathé AA: Cerebrospinal fluid neuropeptide Y-like immunoreactivity correlates with impulsive aggression in human subjects. Biological psychiatry 2012; 72:997-1003

13. Cotton CH, Flint $J$ \& Campbell TG: Is there an association between NPY and neuroticism? Nature 2009; 458:E6

14. Derogatis LR, Melisaratos N: The brief symptom inventory: an introductory report. Psychological medicine. 1983; 13:595-605

15. Domschke K, Dannlowski U, Hohoff C, Ohrmann P, Bauer J, Kugel H et al.: Neuropeptide Y (NPY) gene: impact on emotional processing and treatment response in anxious depress. Eur Nuropsychophmacol 2012; 20:301-9

16. Dzubur-Kulenovic A, Agani F, Avidbegovic E, Jakovljevic M, Babic D, Kucukalic A et al.: Molecular Mechanisms of 
Posttraumatic Stress Disorder (PTSD) as a Basis for Individualized and Personalized Therapy: Rationale, Design and Methods of the South Eastern Europe (SEE)-PTSD Study. Psychiatr Danub 2016; 28:154-163

17. Eaton K, Sallee FR \& Sah R: Relevance of neuropeptide $Y$ (NPY) in psychiatry. Current topics in medicinal chemistry 2007; 7:1645-1659

18. Egan MF, Kojima M, Callicott JH, Goldberg TE, Kolachana BS, Bertolino A et al.: The BDNF val66met polymorphism affects activity-dependent secretion of BDNF and human memory and hippocampal function. Cell 2003; 112:257-269

19. Gehlert DR: Introduction to the reviews on neuropeptide $Y$. Neuropeptides 2004; 38:135-140

20. Goldstein RB, Smith SM, Chou SP, Saha TD, Jung J, Zhang $H$ et al.: The epidemiology of DSM-5 posttraumatic stress disorder in the United States: results from the National Epidemiologic Survey on Alcohol and Related Conditions-III. Social psychiatry and psychiatric epidemiology 2016; 51:1137-1148

21. Grouzmann $E \&$ B Brakch N: NPY processing in neuronal and non-neuronal tissues by proconvertases. In the NPY Family of Peptides in Immune Disorders, Inflammation, Angiogenesis and Cancer 2005; pp 63-74

22. Hansson AC, Cippitelli A, Sommer WH, Fedeli A, Björk K, Soverchia L et al.: Variation at the rat Crhrl locus and sensitivity to relapse into alcohol seeking induced by environmental stress. Proceedings of the National Academy of Sciences 2006; 103:15236-15241

23. Heilig M: The NPY system in stress, anxiety and depression. Neuropeptides 2004; 38:213-224

24. Huang EJ \& Reichardt LF: Neurotrophins: roles in neuronal development and function. Annual review of neuroscience 2001; 24:677-736

25. Huang Q, Liao J, Liu Y, Liang H, Ma P \& Pan J: Plasma neuropeptide $Y$ levels in Chinese patients with primary insomnia. Sleep and Breathing 2015; 19:617-622

26. Jiang $H$, Chen $S$, Li C, Lu N, Yue Y, Yin Y et al.: The serum protein levels of the $t P A-B D N F$ pathway are implicated in depression and antidepressant treatment. Translational psychiatry 2017; 7:e1079

27. Kask A, Harro J, von Hörsten S, Redrobe JP, Dumont $Y$ \& Quirion R: The neurocircuitry and receptor subtypes mediating anxiolytic-like effects of neuropeptide Y. Neuroscience \& Biobehavioral Reviews 2002; 26:259-283

28. Kessler RC, Sonnega A, Bromet E, Hughes $M \&$ Nelson CB. Posttraumatic stress disorder in the National Comorbidity Survey. Archives of general psychiatry 1995: 52:1048-1060

29. Kessler RC, Berglund P, Demler O, Jin R, Merikangas KR \& Walters EE: Lifetime prevalence and age-of-onset distributions of DSM-IV disorders in the National Comorbidity Survey Replication. Archives of General Psychiatry 2005; 62:593-602

30. Kremen WS, Koenen KC, Afari $N$ \& Lyons MJ: Twin studies of posttraumatic stress disorder: differentiating vulnerability factors from sequelae. Neuropharmacology 2012; 62:647-653

31. Liu QR, Walther D, Drgon T, Polesskaya O, Lesnick TG, Strain KJ et al.: Human brain derived neurotrophic factor (BDNF) genes, splicing patterns, and assessments of associations with substance abuse and Parkinson's Disease. American Journal of Medical Genetics Part B: Neuropsychiatric Genetics 2005; 134:93-103
32. Morgan CA, Rasmusson AM, Wang S, Hoyt G, Hauger RL \& Hazlett G: Neuropeptide-Y, cortisol, and subjective distress in humans exposed to acute stress: replication and extension of previous report. Biological Psychiatry 2002; 52:136-142

33. Mühlberger A, Andreatta M, Ewald H, Glotzbach-Schoon E, Tröger C, Baumann $C$ et al.: The BDNF Val66Met polymorphism modulates the generalization of cued fear responses to a novel context. Neuropsychopharmacology 2014; 39:1187-1195

34. Nikisch G, Agren H, Eap CB, Czernik A, Baumann P \& Mathé AA: Neuropeptide $Y$ and corticotropin-releasing hormone in CSF mark response to antidepressive treatment with citalopram. International Journal of Neuropsychopharmacology 2005; 8:403-410

35. Nulk M, Schuh W, Burrell LM \& Matthews MD: Effects of Neuropeptide Y on Resilience to PTSD. West Point Resilience Project (PL488E3) 2011 West Point, NY: United States Military Academy, 2011

36. Okubo T\& Harada S: Polymorphism of the Neuropeptide $Y$ Gene: An Association Study with Alcohol Withdrawal. Alcoholism: Clinical and Experimental Research 2001; 25:59S-62S

37. Peters J, Dieppa-Perea LM, Melendez LM \& Quirk GJ: Induction of fear extinction with hippocampal-infralimbic BDNF. Science 2010; 328:1288-1290

38. Pivac N, Kim B, Nedić G, Ho Joo Y, Kozarić-Kovačić D, Pyo Hong $J$ et al.: Ethnic differences in brainderived neurotrophic factor Val66Met polymorphism in Croatian and Korean healthy participants. Croatian Medical Journal 2009; 50:49-54

39. Priebe S, Janković-Gavrilović J, Schützwohl M, Galeazzi $M G$, Lečić-Toševski D, Ajduković D et al.: Study of longterm clinical and social outcomes after war experiences in ex-Yugoslavia: methods of the 'CONNECT' project. Psihijatrija Danas 2004; 36:101-110

40. Protopopescu X, Pan H, Tuescher O, Cloitre M, Goldstein $M$, Engelien $W$ et al.: Differential time courses and specificity of amygdala activity in posttraumatic stress disorder subjects and normal control subjects. Biological Psychiatry 2005; 57:464-473

41. Rasmusson AM, Hauger RL, Morgan CA, Bremner JD, Charney DS \& Southwick SM: Low baseline and yohimbine-stimulated plasma neuropeptide Y (NPY) levels in combat-related PTSD. Biological Psychiatry 2000; 47:526-539

42. Sah R, Ekhator NN, Strawn JR, Sallee FR, Baker DG, Horn PS et al.: Low cerebrospinal fluid neuropeptide $Y$ concentrations in posttraumatic stress disorder. Biological Psychiatry 2009; 66:705-707

43. Sah $R$ \& Geracioti TD: Neuropeptide $Y$ and posttraumatic stress disorder. Molecular Psychiatry 2015; 18:646-655

44. Sah R, Ekhator NN, Jefferson-Wilson L, Horn PS, Geracioti TD: Cerebrospinal fluid neuropeptide $Y$ in combat veterans with and without posttraumatic stress disorder. Psychoneuroendocrinology 2014; 40:277-283

45. Sajdyk TJ, Shekhar A \& Gehlert DR: Interactions between $N P Y$ and $C R F$ in the amygdala to regulate emotionality. Neuropeptides 2004; 38:225-234

46. Schmeltzer SN, Herman JP \& Sah R: Neuropeptide Y (NPY) and posttraumatic stress disorder (PTSD): a translational update. Experimental Neurology 2016; 284:196-210

47. Shimizu E, Hashimoto $K \&$ Iyo M: Ethnic difference of the BDNF 196G/A (val66met) polymorphism frequencies: the 
possibility to explain ethnic mental traits. American Journal of Medical Genetics Part B: Neuropsychiatric Genetics 2004; 126:122-123

48. Soliman F, Glatt CE, Bath KG, Levita L, Jones RM, Pattwell SS et al.: A genetic variant BDNF polymorphism alters extinction learning in both mouse and human. Science 2010; 327:863-866

49. Sommer WH, Lidström J, Sun H, Passer D, Eskay R, Parker CJS et al.: Human NPY promoter variation rs 16147: T>C as a moderator of prefrontal NPY gene expression and negative affect. Human Mutation 2010; 31:E1594-E1608

50. Tatemoto K, Carlquist M, Mutt V: Neuropeptide Y-a novel brain peptide with structural similarities to peptide $Y Y$ and pancreatic polypeptide. Nature 1982; 296:659-60

51. Thoenen H: Neurotrophins and neuronal plasticity. Science New York then Washington 1995; pp.593-593

52. Tiwari AK, Brandl EJ, Weber C, Likhodi O, Zai CC, Hahn MK et al.: Association of a functional polymorphism in neuropeptide $Y$ with antipsychotic-induced weight gain in schizophrenia patients. Journal of clinical psychopharmacology 2013; 33:11-17

53. Tsai SJ: The P11, tPA/plasminogen system and brain-derived neurotrophic factor: Implications for the pathogenesis of major depression and the therapeutic mechanism of antidepressants. Medical Hypotheses 2007; 68:180-183

54. U.S. Department of Veterans Affairs: Epidemiology of PTSD, 2015. www.ptsd.va.gov
55. Witt SH, Buchmann AF, Blomeyer D, Nieratschker V, Treutlein J, Esser $G$ et al.: An interaction between a neuropeptide $Y$ gene polymorphism and early adversity modulates endocrine stress responses. Psychoneuroendocrinology 2011; 36:1010-20

56. Widerlöv E, Lindström LH, Wahlestedt $C$ \& Ekman R: Neuropeptide $Y$ and peptide $Y Y$ as possible cerebrospinal fluid markers for major depression and schizophrenia, respectively. Journal of Psychiatric Research 1988; 22:69-79

57. World Medical Association. World Medical Association Declaration of Helsinki: ethical principles for medical research involving human subjects. Jama 2013; 310:2191

58. Xu K, Hong KA, Zhou Z, Hauger RL, Goldman D \& Sinha $R$ : Genetic modulation of plasma NPY stress response is suppressed in substance abuse: association with clinical outcomes. Psychoneuroendocrinology 2012; 37:554-564

59. Yehuda R, Brand $S$ \& Yang RK: Plasma neuropeptide $Y$ concentrations in combat exposed veterans: relationship to trauma exposure, recovery from PTSD, and coping. Biological Psychiatry 2006; 59:660-663

60. Zhang L, Xiao XL \& Xian ZH: Post-traumatic stress disorderriskandbrain-derivedneurotrophicfactor Val66Met, World J Psychiatry 2016; 6:1-6

61. Zhou Z, Zhu G, Hariri AR, Enoch MA, Scott D, Sinha R et al.: Genetic variation in human NPY expression affects stress response and emotion. Nature 2008; 452:997-1001

Correspondence:

Elma Feric Bojic, MD, PhD

International Burch University, Department of Genetics and Bioengineering

Francuske revolucije bb, 71000 Sarajevo, Bosnia and Herzegovina

E-mail:elma.feric@gmail.com 